\title{
EL CID = EL LEÓN: ¿EPÍTETO ÁRABE DEL CAMPEADOR?
}

Por

MÍKEL DE EPALZA

\section{TEXTO REEDITADO}

Por razones tipográficas, el artículo de $\mathrm{M}$. de Epalza «El Cid = El León: ¿epiteto árabe del Campeador", Hispanic Review, Philadelphia, 45/1, 1977, 67-75, se reproduce como apéndice del artículo del mismo autor «Etimología árabe del Cid, como antropónimo ("el LEÓN") y como topónimo ("el SEÑOR y/o GOBERNADOR almohade")", en este mismo volumen 7 (1990), pp. 157-170 de la revista SHARQ ALANDALUS. ESTUDIOS ÁRABES. 
NADIE ha puesto nunca en duda el origen árabe de la palabra Cid, epíteto o título del caballero castellano Rodrigo Díaz, personaje político y militar de fines del siglo xI y héroe épico en múltiples géneros literarios. ${ }^{1}$

Ramón Menéndez Pidal, suprema autoridad en estos estudios cidianos, escribe: "Entre esos moros adictos, del partido andalusi, y entre esos cristianos expatriados nacio en las fronteras levantinas el nombre familiar y afectuoso del héroe: Cid 'señor,' Cidi 'mi señor,' le llamaban los moros; mio Cid le llamaban los cristianos con expresión híbrida, medio romance medio árabe. Pero este era un nombre reservado a la respetuosa intimidad vasallal.".

Explica a continuación que sólo el epíteto Campeador figura en los documentos y textos coetáneos, tanto latinos como árabes, y que Cid aparece por primera vez en el Cantar de Mio Cid y, sólo mucho más tarde, en la prosa castellana o latina de las crónicas. ${ }^{3}$

* Este trabajo fue presentado en el Congreso de la Asociación Internacional de Hispanistas de Burdeos (septiembre 1974).

${ }^{1}$ Pronto tendria que salir un libro, en la S.N.E.D. de Argelia, que tiene por título precisamente Le Cid: Personnage historique et littéraire, preparado con la Sra. Guellouz, de la Universidad de Constantina, cuando enseñábamos literatura comparada en la Universidad de Túnez. Es un estudio y una antología sobre el persumaje, en diversos géneros literarios (poesía, teatro, prosa, historia . . .) y en diversas lenguas, traducido al francés.

2 R. Menéndez Pidal, La España del Cid, 7 ed. (Madrid, 1969), n, 5.55.

3 "Mientras Campeador, Campealor, Campidoctor era titulo oficial, que desde la mocedad se aplicaba a Rodrigo, y que él mismo usaba en sus documeritos, a la vez que lo empleaban los historiógrafos coetáneos, tanto latinos como arabes, el nombre de Cid no se usb oficialmente en vida del héroe. Sólo más tarde lo adopta el poeta de Medinaceli, como nota de color. Fn la prosa, ya se atreve a usarlo, 
En su exhaustivo vocabulario lexicográfico del Cantar, inieia el articulo "Cid" con la descripción siguiente: "título honorifico, derivado del árabe şid 'señor' ; lleváronlo varios personajes cristianos, sin duda por haber vivido entre los moros o tener vasallos musulmanes." Cita numerosos y heterogéneos ejemplos, tomados de las obras cidianas o de otros textos de la época." La etimología árabe sayyid o sayyidī ("señor" o "mi señor") le parece, pues, procedente, por derivación normal: "El sin árabe se representa regularmente por c: Cid, caga."s

Los hispanistas y los arabistas siguen esta opinión generalmente admitida, aún los que estudian más de cerca este epíteto, como A. Galmés de Fuentes." Los autores árabes antiguos nunca le mencionan con este título, quizás por las razones que apuntaremos más adelante; los autores árabes modernos adoptan la ortografía s-y-d, como transcripción árabe del término europeo conocido $C i d$, pero no lo vocalizan, ni suelen opinar sobre la palabra árabe original..$^{7}$

alrededor del 1200, el Liber Regum, escrito también, como el Poema, hacia la frontera de Levante, en el este de Navarra o en Aragón. Tenemos que llegar a la Primera Crónica General, hacia 1270, para encontrar generalizado en Castilla el nombre familiar y poético con que después se universalizó la fama de Rodrigo en la historia y en la literatura" (Menéndez Pidal, La España del Cid, pág. 555). El mismo autor hace notar que este epiteto no figura en la Historia Roderici, según él casi coetánea del Cid, y sí en una crónica hebrea tardía de José ben Zaddiq de Arévalo (La España del Cid, pags. 918, 161). "En hebreo, 'Cídi' equivale al afectuoso título 'mio Cid,' esto es, 'mi Señor,' expresión medio castellana, medio mora, con que el héroe era designado familiarmente por sus vasallos en las fronteras" (La España del Cid, pág. 161).

4. Menćndez Pidal, Cantar de Mio Cid. Texto, Gramática y Vocabulario, 4* ed. (Madrid, 1969), II, 574-77.

- Cantar de Mro Cid, I, 175.

- A. Galmés de Fuentes, "Epica árabe y épica castellana: problema crítico de sus posibles relaciones," en La poesía épica e la sua formazione (Roma, 1970), pags. 212-14.

${ }^{7}$ Véase, como ejemplos, el poema de Zākì Al-Mahāsini: "Elegía a la muerte de don Ramón Menéndez Pidal" (publicado en una revista siria y traduciclo por Leonor Martinez Martín, Antología de pocsia árabe contemporünca [Madrid, 1972], págs. 142-44) o las menciones de la obra de teatro de Corneille en los libros de literatura comparada de Muhammad Ganimī Al-Hilāl, Al-Adab al-muqăran [La literatura comparada], 3* ed., (Cairo, 1963), págs. 300-301, o de Muhammad Mufïd Al-Shubāshi, Rihlat al-adab al-'arab̄i ilà Urübbā [El paso de la literatura árabe a Europa] (Cairo, 1968), págs. 241 y ss., en que el autor mismo siente la necesidad de afirmar que Cid "es, (1) mismo, un nombre árabe, como es patente," aunque no indiea claramente lit palabra farube original. 
Solamente en el momento de redactar definitivamente estas líneas, y revisando las opiniones de diversos autores árabes modernos para ver confirmada o no la hipótesis que vamos a presentar aqui, hemos encontrado a un autor que analiza con bastante cuidado este tema y emite-entre otras-la hipótesis nuestra, sin detenerse mucho en ella. Efectivamente, el Dr. Tahar Makki, de la Univer sidad de El Cairo, estudia este tema en el capítulo "Dos títulos. El Cid y El Campeador" de la inteligente y luminosa introducción a su traducción árabe del Cantar de Mio Cid. ${ }^{8}$

Tahar Makki vocaliza siempre al-sid, y lo distingue bien de sayyid. ${ }^{\circ}$ Pero cuando ya llega a analizar más detenidamente ol significado o etimología de la palabra, va mucho más lejos que sus predecesores, con comparaciones interesantes con diversos dialectos árabes. Se detiene ampliamente en la etimologfa sayyid "señor," mostrando también algunas de la dificultades que hay en aceptarla : es un caso raro en árabe; no es normal, por ningún concepto. Y junto a eso presenta también "que la palabra $a l$-sĩd, que se aplica a Rodrigo no es una evolución fonética de la palabra sayyid, sino que es una palabra original y antigua, que no se presta a discusión. Significa el lobo o el león en algunos textos." "10 Cita ejemplos de poetas antiguos y muestra como ambos calificativos árabes pueden aplicarse a Rodrigo, especialmente el de lobo, que se aplicó a otros cabecillas militares del Levante musulmán español en la Edad Media (el famoso Rey Lobo o Lubb, de Murcia). Pero no se detiene más en analizar esta hipótesis.

Es precisamente esta hipótesis (la de Cid como "león" y no primariamente como "lobo") la que queremos presentar aquí, a pesar de la casi absoluta unanimidad de los autores en favor de Cid como "señor." Pero tampoco queremos dar a esta hipótesis más validez de la que tiene, dado que está hecha de serias convergencias, pero tampoco cuenta, por ahora, con una argumentación definitiva.

El hecho es que dos realidades de la convivencia habitual con el mundo árabe magrebí nos han hecho sospechar también que el epiteto árabe del Campeador puede tener tanta o más relación con el nombre árabe sĩd o ş̃d "león" que con ol sayyid "señor," cuyo

B T. A. Makki, Malhamat al-Sĩd: A wroal malhama andalusiya kutibal fĩ al-luga al-qashtālīya [Epopeya del Cid: Primera epopeya andalusí escrita en lengua castellana] (Cairo, 1970), págs. 173-82.

- Malhamat al-Síd, pág. 141.

10 Malhamat al-Sîd, pág. 176. 
esquema consonántico árabe es el mismo, pero que se vocaliza de distinta manera.

Lo primero es que los estudiantes de los colegios tunecinos, que tienen Le Cid de Corneille en los programas de lengua y literatura francesa-muy importantes en Túnez-dicen en seguida, sonriendo como ante cosa bien conocida: "Cid, monsieur, c'est le lion en arabe." Para ellos sĩd o sid significa "león" en árabe popular, como en todo el Norte de África; es el nombre más popular para el león, en Túnez, mientras que en los otros países del Mágreb es nombre conocido, pero hay también otros nombres para ese animal. Los profesores, en esos casos, suelen corregirles: "Mais non, c'est seigneur"; pero es evidente que el sid "león" es un epiteto guerrero que les resulta más adecuado a los muchachos para el personaje "matamoros" que se presenta en la obra de Corneille, que el término sayyid "Beñor," del árabe clásico, pronunciado también sīd, sĩdĩ o sī, en la vida o lenguaje normal magrebí.

Por otra parte, el título de sayyid o sayyid̄ (comunmente pronunciado $s \bar{\imath} d \bar{\imath}$ ), se da, como vocativo, indistintamente a árabes o no-árabes, a musulmanes o cristianos, como lo nota también el profesor Makki. Pero precediendo a un nombre-no a un apollido-se suele reservar a los musulmanes, por el sentido de respeto, veneración religiosa y soberanía que supone. Es título que se da a ancianos, autoridades $\mathrm{y}$, particularmente, a los santos del Islam (equivale a nuestro "san fulano"). Por tanto, a los of́dos de un musulmán normal, decir sīi Ruy Díaz-no en vocativo solo, sino con el nombre o apellido-suena tan extrafio como para nosotros San Mahoma de La Meca, o Don Alımed Amín, o Don Mustafá Chelebi. Lo mismo diríse de "Fl Señor" como epiteto, que numca aparece, como se ha dicho, en las fuentas árabes medievales. Quizás sea esto fruto de la separación y antagonismo religioso-cultural de estos altimos siglos, y quizás no chocaría tanto en el contexto abigarrado del siglo XI peninsular, como parecen indicarlo los numerosos documentos recogidos por Menéndez Pidal, en los que aparece ese título de "mi Señor = mío Cid o Cide," aunque el mismo docto maestro reconoce que algunos de ellos podrian ser "de otro origen, sin duda."11

Pero razones de más peso abogan por una relación íntima entre las palabras $C i d$ y sid. ${ }^{12}$

"Menéndez Pidal, Cantar de Mío Cid, n, 574-77.

12 El dialectal magrebino actual conoce mas sĩd (con s enfática), que significa también "león" y "cazador," igual que sā'id y otros derivados de la misma ruí. 
Sīd "león" es un auténtico epíteto militar y guerrero, y sabemos la importancia que tiene esto en la épica hispánica, después de los trabajos de A. Galmés de Fuentes y F. Marcos Marín, en su relación con la épica árabe. ${ }^{13} S i d$ "león" pertenece a la misma raíz que "señor" y "jefe." Es epíteto muy corriente en el mundo árabe y ha pasado a ser un apellido, en su forma árabe clásica asad (por ej., el militar Hafedh El-Asad, presidente de Siria) o en su forma turca arslan (Emir Arslan, de la dinastía drusa del Líbano). En su forma sĩd (con 8 enfática) es un apellido corriente en todo el Mágreb árabe, con el mismo sentido de "león."

Con $s$ sibilante, fue el nombre de un poligrafo muy conocido, contemporáneo de Rodrigo, Ibn al-Sid al-Bațalyausi (de Badajoz). Nació en 1052, circulo mucho por el Levante español (Albarracín, Zaragoza) hasta que se instaló en Valencia, donde murió a una edad avanzada, en 1127.14 Varios diccionarios árabes suelen mencionar, por otra parte, el paso semántico de sīd "león" a sīd "señor," en el lenguaje corriente. Sin necesidad de hacer un estudio especial sobre el uso de esta palabra en la Edad Media-estudio que sería muy interesante $^{15}$-se puede afirmar que el paso de una a otra acepción podía ser muy corriente en el medioevo español.

Porque sabemos-y esto es lo curioso-que las características del león fueron aplicadas directamente a nuestro personaje épico, Mío Cid Rodrigo Díaz de Bivar. El Cantar de Mio Cid nos presenta,

${ }^{27}$ Galmés de Fuentes, Epica árabe y épica castellana, págs. 195-258; F. Marcos Marín, Poesía narrativa arabe y épica hispánica: Elementos árabcs en los orgenes de la epica hispanica (Madrid, 1971), y "Wl autospellido en la épic* árabe," Bolctin de la Asociación Española de Orientalistas, vi (1970), 208-13.

"Es autor muy conocido. Véuse, por ejemplo, E. Ciarcín (Gómez, Ibn AlZaqqāq: Pocsias, o la tesis, nún inédita, de M. Muhammad Al-Amin, "Obra y vida de Abu Muhamad Abd Allah Ibn al-Sid Al-Batalyawsi" (resumen de la tesis en la Revista de la Universidad de Madrid, xir, 48 (1963), 777-78). El professor Makki, en Malhamat al-Sĩd (págs. 173-82), coincide en el paralelismo con Ibn al-Sid.

${ }^{15}$ El professor F. de la Granja tiene la amabilidad de señalarme que la pslabra $s \bar{d} d$ apenas aparece en los textos escritos en árabe clásico y que tampoco figura en el vocabulario de dialectal granadino de Pedro de Alcalá. En cambio "león," con sus diversos nombres, es un epiteto muy corriente en árabe, ya en las fuentes antiguas, como se puede ver en G. Gabrieli, Il nome proprio arabo-musuimano (Roma, 1915). Los diccionarios modernos, de árabe clásico y de dialectal magrebi, recogen siempre las dos palabras: sĩd "señor, lobo, león" y şīl "cazador, león," con varios epitetos derivados similares, que provienen de los dos sentidus de las raices $s-w-d$ (señorí) y $s-y-d$ (caza). 
al principio de su tercera parte, el enfrentamiento del Cid con un león, escapado en el palacio de Valencia. Es un episodio que ha hecho correr mucha tinta, y no sin razón muchos autores como C. Bandera Gromez ${ }^{16}$ y L. Rubio García ${ }^{17}$ le atribuyen, recientemente, una importancia simbólica extraordinaria en el conjunto literario del Cantar.

Ya E. de Chasca notaba que, estilísticamente, los verbos empleados en ese texto "nos han llevado a un punto único de todo el poema, porque corresponden al único momento en que el Cid está para hermanarse plenamente con los héroes épicos de un mundo maravilloso,"18 y está de acuerdo con Gilman ${ }^{19}$ en que hay una identificación del Cid con el león en "una nueva dimensión épica en la que la figura del Cid, casi rebasando ya to humano 'hace rumbo al mito'."20

Los análisis y la erudición de C. Bandera han mostrado también el carácter eminentemente épico de este episodio dentro del conjunto de la simbología medieval: constituye casi el único momento maravilloso dentro de la línea general realista del poema. En esta línea realista, se han hecho alardes de erudición para encontrar antecedentes históricos de leones que salen de sus jaulas y son domados por un caballero."1 Pero muy acertadamente dice el propio Menéndez Pidal que "el estilo épico, que gusta de colocar la narración in medias res, puede nombrar por primera vez el león (v. 2282), como si todos supiesen ya de él."22

Queda así en pie la conclusión de Bandera de que "está claro que el episodio del león es mucho más que una circunstancia novelesca caprichosamente incluida por el poeta para dar, habríamos de

${ }^{16}$ C. Bandera Gómez, El "Poema de Mio Cid": poesía, historia, mito (Madrid, 1969), púgs. 82-114.

${ }^{17}$ L. Rubio Garcia, Realidad y fantasia en el "Poema de Mio Cid" (Murcia, 1972), pags. 294-95, resumido en sus Estudios sobre la Edad Media española (Murcia, 1973).

${ }^{18}$ E. de Chasca, El arte juglaresco en el "Cantar de Mio Cid" (Madrid, 1967), pág. 299.

"S. Gilman, Tiempo y formas temporales en el "Poema del Cid" (Madrid, 1961), págs. 131-41.

${ }^{20}$ Citando a Américo Castro, "Poesía y realidad en el 'Poema del Cid'," Tierra Firme, I (1936).

${ }^{21}$ Menéndez Pidal, Cantar de Mro Cid, Ir, 731; En torno al poema del Cid (Madrid, 1973), págs. 28-29.

$2 z$ Cantar de Mro Cid, r, 299. 
suponer, algo más de variedad a su relato."23 "Pone de manifesto ... el carácter leonino del Campeador . . . [Para el juglar] como el león, su héroe es fuerte con el fuerte; es prudente, es magnánimo, es generoso y, sobre todo, es vigilante y sagaz."

Este tono épico fundamental fue glosado intuitivamente por el romancero, parafraseando el verso que compendia la opinión general en la corte del Campeador, a raíz del suceso: "A maravilla lo han quantos que i son" (v. 2302):

\section{Aturdido está el gentío \\ Viendo lo tal, no catando \\ Que ambos eran leones, \\ Mas el Cid era el más bravo. ${ }^{26}$}

Lo que hay que admirar aquí es que la comparación tiene quizás una base filológica en el nombre o epíteto mismo del Cid, "el león," epiteto guerrero y militar, epíteto épico por excelencia.

Así se explicaría también que fuera ese nombre el grito guerrero del Campeador, cuando peleaba en tierras árabes: "Yo so Ruy Diaz, El Çid Campeador de Biuar" (v. 721), "Ca yo so Ruydiaz, myo Cid el de Biuar" (v. 1140). ${ }^{26}$

Por considerar precisamente $C i d$ como un título honorffico simple-"seffor"-y no como epíteto militar al igual que Campeador, puede afirmar E. de Chasca que 'la expresión 'mio Cid,' sin dejar de celebrar al héroe, suele corresponder más al tratamiento habitual que al elogio especial."27 Todo su magnifico análisis del epiteto en el Cantar debería revisarse en función del carácter épico acentuado del Cid, el León.

Evidentemente, esta hipótesis, por muy sugerente que sea, no deja de plantear algunos problemas.

"Banders Gómez, El "Poema de Mío Cid," pág. 111. Ni menos aún con el sentido cómico que apunta Menéndez Pidal (En torno al poema, págs. 221-22), que se desarrolló en el romancero (cf. Romancero General, BAE, x [1945], 542-43) y que Quevedo lieva al extremo de la burla sin que quede ya el menor rasgo o respeto del carácter épico del Cid (Pauura de los Condes de Carrión, en Obras completas [Madrid, 1961], II, 325-36).

* Bandera Gómez, El "Pocma de Mio Cid," págs. 112-14.

${ }^{25}$ Romancero General, BAE, x (1945), 542-43.

20 Véase explicación de estos gritos guerreros en Menéndez Pidal, Cantar de Mio Cid, n, 576.

" de Chasca, El arte juglaresco, pág. 173. 
El primero"sería el del origen histórico del epíteto. Sólo después nos podemos plantear el del origen del posesivo mio Cid, que evidentemente no cuadra con la hipótesis de "El Cid = El León."

En ambos temas, solo se pueden presentar por ahora hipótesis, mientras no se vea más claro en la actual polémica del origen del Cantar y su relación con las demás fuentes cidianas. No hay más que citar algunas posiciones extremas, de estos últimos años, para ver en qué nebulosidades andamos aún sobre estos temas: $R$. Menéndez Pidal con su hipótesis de los dos juglares de principios del siglo xIr, el de Medinaceli y el de San Esteban de Gormaz ${ }^{28}$; H. Mones con su hipótesis del ministro árabe del Cid en Valencia, monje de Cardeña e iniciador de la "leyenda"20; L. Rubio García que cree por motivos diferentes en esa "leyenda de Cardeña," mientras que $A$. Ubieto Arteta le da un origen más tardío y decididamente aragonés."

Evidentemente, la teoría del professor Hussein Mones, de la Universidad de Koweit, encajaría más lógicamente con la hipótesis que presentamos. Así podrían concebirse tres etapas en la formación y evolución literaria del epíteto $C i d$ aplicado al Campeador. Aqui ya sólo nos movemos en la pura hipótesis, dentro de un terreno en que tampoco las creencias anteriores nos parecen más fundadas. Sería una hipótesis coherente, pero nada convincente : no es lo mismo traer razones en favor de una etimologia-que nos parece muy probable-y presentar una teoría sobre el origen de esa etimologia, a partir de solas coherencias hipotéticas.

Pero atrevámonos con esa "coherencia."

Es muy posible que se le aplicara a Rodrigo en vida el epiteto árabe sìd (león, señor) o, más bien, șïd (león, cazador). Lo habrían aplicado a Rodrigo los árabes, quizás ya en Zaragoza o en Sevilla, como epiteto guerrero árabe normal, traducción árabe del epiteto guerrero romance Campeador. Esto se explicaría en el ambiente cortesano de los taifas levantinos, donde el término romance-que luego utilizaron los cronistas árabes en su prosa-no se prestaría a loas populares ni a composiciones poéticas en árabe. Que sa le haya

${ }^{28}$ Aún recientemente en Menéndez Pidal, En torno al poema.

20 H. Mones, "De nuevo sobre las fuentes árabes de la historia del Cid," en Revista del Instituto Egipcio de Estudios Islámicos, (Madrid), 2 (1954), 99 ss.

${ }^{30}$ Véare n. 17 arriba.

"A. Ubieto Arteta, El "Cantar de Mío Cid" y algunos problemas históricos (Valencia, 1973), págs. 171-72. 
llamado sĩd o sĩd, en árabe dialectal, y no asad, en árabe clásico, es problema de menor importancia.

Siguiendo las hipótesis de una tradición cidiana de origen valenciano, ya sea en Cardeña, ya sea en Aragón, ya sea en el límite de Aragón y Castilla, verfamos que el origen del poema y de sus fuentes pueden haber conocido el sentido árabe del epíteto aplicado al Campeador. Asi se comprendería mejor la tradición histórica del episodio del loón y su importancia épica en el Cantar.

Pero, en ambiente castellano, la significación de Cid "loón" desaparecería rápidamente para dar lugar a la de Cid "sefor," que se conocla de una forma más general, aún fuera de la Espatia de lengua árabe. Por eso el autor definitivo del Cantar ya debis de utilizar el epiteto como un nombre corriente o aplicarle el posesivo, aunque se puede aún notar en la gesta el sustrato histórico de bo antecedentes contemporáneos al hóroe.

Son hipótesis, no mucho menos fundadas que las que se han emitido hasta ahora.

Estas modestas reflexiones, que podrán ser confirmadas o anuladas por argumentos de personas más expertas, por su formación - recursos bibliográficos, permiten al menos el plantearse un problema que está-a nuestro parecer-aún por solucionar. Y tratíndose del título de uno de los personajes históricos y litersios mós importantes de la cultura hispánica, toda investigación por nimis que sea puede estar justificada.

Universidad de Argel, Argelia

Misel de Epalza 